\title{
Molecular Mechanisms of Metaplasia, Differentiation and Hyperplasia of Goblet Cellin Allergic Asthma
}

Toshiharu Hayashi*

Department of Veterinary Medicine, Yamaguchi University, Japan

\begin{abstract}
Bronchial allergic asthma (asthma) is an airway inflammation characterized by airflow obstruction of variable degrees with bronchial hyper-responsiveness and is induced by a complex interaction of environmental and genetic factors. Asthma of the human can be divided into an immediate- and a late-phase reaction, and some of the patients develop a late-phase reaction after a symptom-free interval. Hallmarks of asthma are mucus overproduction by goblet cells associated with responses of helper T(Th)2 cells. Mucus hypersecretion from goblet cells themselves or by metaplasia and/or hyperplasia of goblet cells appears to be associated with disease severity in asthma, because mucus production by those cells in local bronchial-bronchiolar lesions causes airway mucus plugging. However, the mechanisms of mucus production are not fully understood. Molecular mechanisms of goblet cell metaplasia, differentiation and hyperplasia will be reviewed in this article. Also, the relationship between allergic inflammation in Th1/Th2 paradigm shift and thymic stromal lymphopoietin (TSLP) was included for the understanding of goblet cell response in asthma. The clarification of mechanisms of mucin production in vivo may lead to the development of novel therapeutic strategies to suppress mucus production in asthma.
\end{abstract}

Keywords: Asthma; Goblet cell; Clara cell; Mucus; Inflammatory Th2; TSLP; Epithelium

\section{Introduction}

Bronchial allergic asthma (asthma) is a prevalent disease and is increasing in developed countries. Asthma is an inflammatory disorder characterized by airflow obstruction of variable degrees with bronchial hyper-responsiveness. Asthma is caused by environmental factors and induced by a combination of genetic and environmental stimuli. Genetic studies have revealed that multiple loci are involved in the etiology of asthma [1]. Athma of the human can be divided into an immediate- and a late-phase reaction, and some of the patients develop a late-phase reaction after a symptom-free interval [2]. Helper T(Th)2 cells play a fundamental role in both immediate and late reactions. Immediate reaction is induced by IgE-mediated increased mast cell response, whereas late response is characterized by recruitment of eosinophils, basophils, and Th2 cells producing cytokines such as IL4, a switch factor for IgE synthesis, and IL-5, an eosinophil growth factor [3]. In addition, late reaction may be allergen dependent and IgE independent. Moreover, Tang et al. [3] reported that the chronic response in asthma is thought to include repeated epithelial shedding, mucus secretion, thickening of the basal lamina, airway wall fibrosis, smooth muscle hypertrophy, angiogenesis and hyperplasia of the submucosal gland. The degree of mucus production appears to be associated with disease severity in patients with asthma [4]. Hallmarks of asthma are goblet cell hyperplasia and mucus overproduction, leading to cough, shortness of breath and wheezing. In the most severe cases of asthma these effects can be dramatic, and pathologic evidence suggests that mucus plugging may be the cause of death in fatal asthma [5]. Goblet cells in the airway epithelium at autopsy were demonstrated to be 30 -fold higher in patients with fatal asthma than those with asthma who died of other causes [5].

Thus, goblet cell responses in asthma play an important role in the pathogenesis of asthma (Figure 1). Recent cellular, molecular and animal-model studies have revealed several cellular events including inflammatory helper Th2 cytokines that are involved in the progression of asthma, leading to goblet cell responses. This article focusses on goblet cells and introduces molecular mechanisms of goblet cell metaplasia, differentiation and hyperplasia in asthma (Figures $2 \mathrm{~A}$ and 2B).

\section{Goblet Cell Function}

In this section general information of goblet cell function will be explained briefly. In the normal human airway, mucus is produced and secreted by mucous (goblet) cells. The submucosal glands in the larger airways also contribute to mucus production. Mucus is composed of water, ions, lipids, proteins, and complexed macromolecular glycoproteins called mucins, which impart viscoelastic and gelforming properties to mucus [6]. More than 20 mucin genes have been identified, and 12 of these have been shown to be expressed in the respiratory epithelium [7]. There are two structurally and functionally distinct classes of mucin such as membrane-bound mucins and secreted mucins. Membrane mucins, which have transmembrane and cytosolic domains, are tethered to the plasma membrane, where they participate in functions such as cellular adhesion, pathogen binding, and signal transduction [8,9]. Proteolytic cleavage or synthesis of alternative splice variants lacking the transmembrane domain can result in release of membrane mucins into the mucous layer [10]. Secreted mucins are synthesized in epithelial cells and stored in intracellular secretory granules until stimulated for release by regulated exocytosis. The gel-forming mucins, MUC5AC and MUC5B, are the most prominent secreted mucins in the respiratory tract. When secreted, gel-forming mucins form a dense macromolecular matrix providing the adhesive and space-occupying properties of the mucous

*Corresponding author: Toshiharu Hayashi, Laboratory of Veterinary Pathology, Joint Faculty of Veterinary Medicine, Yamaguchi University, 1677-1, Yoshida, Yamaguchi, 753-8515, Japan, Tel/Fax: +81 83933 5890; E-mail: hayasi@yamaguchi-u.ac.jp

Received August 01, 2012; Accepted October 25, 2012; Published November 30,2012

Citation: Hayashi T (2012) Molecular Mechanisms of Metaplasia, Differentiation and Hyperplasia of Goblet Cellin Allergic Asthma. J Aller Ther 3:121. doi:10.4172/21556121.1000121

Copyright: ( $) 2012$ Hayashi T. This is an open-access article distributed under the terms of the Creative Commons Attribution License, which permits unrestricted use, distribution, and reproduction in any medium, provided the original author and source are credited. 

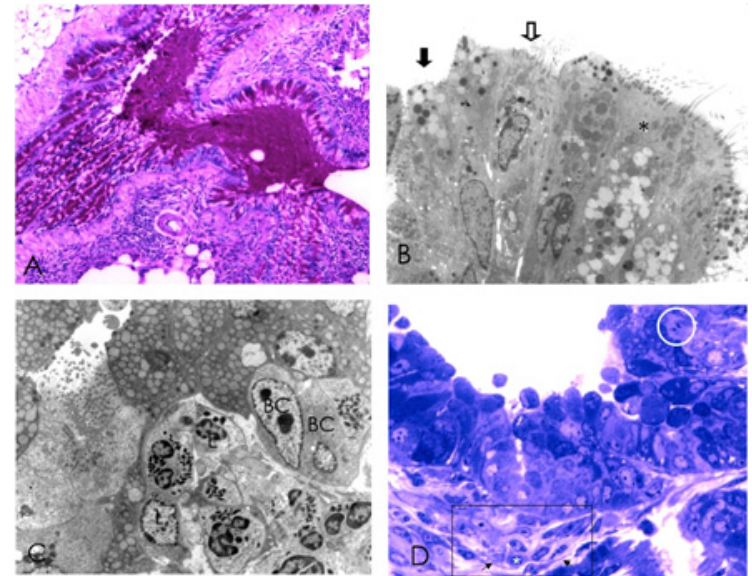

Figure 1: Asthmatic bronchial lesions of a late asthma model mouse (A). Desquamated epithelial cells and mucusin the bronchial lumens (Lu). Goblet cell metaplasia (B) from Clara cells (black arrows) with secretory granules and ciliated cells (white arrow). Ciliated cells contain mucin and secretory granules (black starmark). Basal cells locate adjacent to basement membrane and are present in the areas of immature Clara cells where infiltration of many eosinophils with lymphocytes (C). Dendritic-like cells (white star mark and arrows indicate cytoplasmic process in rectangle of (D) and mitosis of basal cells (white circle) can be seen. BC: Basal Cell, E: Eosinophils; L: Lymphocyte; A: PAS; D: TB.

gel layer [11]. Gel-forming mucins are synthesized and stored in a condensed form as large, covalent disulfide-linked oligomers and multimers in cytoplasmic vesicles at the apical surface of the goblet cell. Numerous inflammatory and humoral mediators have been shown to stimulate mucin secretion including cholinergic agonists, lipid mediators, oxidants, cytokines, neuropeptides, ATP and UTP, bacterial products, neutrophil elastase, and inhaled pollutants including other allergens [12]. Mucin exocytosis is a complex process controlled by a key regulatory molecule, myristoylated alanine-rich $\mathrm{C}$ kinase substrate (MARCKS), which is bound to the cytoplasmic surface of the plasma membrane in the constitutive state. MARCKS was shown to be essential for mucin release in vitro [13] and in vivo in a mouse model of allergic airway inflammation [14]. Mucus hyperproduction can impair mucociliary clearance causing retention of pathogens and toxic particles and may also result in airway obstruction leading to ventilation-perfusion mismatching.

\section{Goblet Cell Morphology}

In this section goblet cell morphology and compositive differences of epithelium in intrapulmonary bronchi between human and mouse will be explained (Table 1). The respiratory system is composed of a tree-like system of branched tubes that carry air to and from the alveoli, where gas exchange takes place. This basic design is conserved among vertebrates, but there are important differences between mouse and human lungs - presumably a result of the very large differences in body size [15], including species difference in distribution of goblet cells. Also there are differences existing between mouse and human airway epithelia such as stem cell/plasticity capabilities [16]. In human, goblet

\begin{tabular}{|l|l|l|l|l|l|}
\hline & Goblet cell & Ciliated cell & Clara cell & Basal cell & $\begin{array}{l}\text { Submucosal } \\
\text { gland }\end{array}$ \\
\hline Human & ++ & +++ & + & ++ & ++ \\
\hline Mouse & + +- & ++ & +++ & +++ & - \\
\hline
\end{tabular}

-:absence, +/-:few, +:a few. ++:moderate,+++: many

Table 1: Differences in cell composition and submucosal gland of intrapulmonary bronchi between human and mouse. cells have many mucin granules and are found throughout the glandular and surface airway epithelia and can be detected histochemically using alcian blue $(\mathrm{AB})$ and periodic acid Schiff (PAS)'s stains. Submucosal glands, which contain a mixture of goblet cells and serous cells, are distributed throughout the cartilaginous airways in humans, but are limited to the laryngeal region of the trachea in mice [15]. In the small airways of humans and in all intrapulmonary bronchi-bronchioles in mice, there are very few goblet cells under basal conditions. In mice, for example, ciliated cells $(\sim 40 \%)$ and nonciliated cells $(\sim 60 \%)$, which are mostly Clara cells, account for the vast majority of airway epithelial cells [17]. In normal specific pathogen-free mice, there were mainly three cell types in the epithelium of the intrapulmonary bronchi-bronchioles such as ciliated, non-ciliated (Clara) and basal cells [18]. The epithelium was reduced in thickness in the more distal airways in human and mouse. Both the ciliated and Clara cells adhering to neighboring cells by desmosomes were seen equally throughout the bronchus and bronchiole. Clara cells with or without a few short microvilli have a lot of smooth endoplasmic reticulum (s.e.r.) and mitochondria, appearing dark with a few or no cristae. A few round, homogeneous fine electrondense secretory granules (S.G.), which do not have a clear membrane bound, corresponding to fine granules (a varying degree) stained with toluidin blue (TB) were also located most regularly in the apical portion of Clara cells. Non-cilliated cells without S.G., which seem to be Clara cells, are often observed. S.G. appeared to be in the process of extrusion into the lumen of the airway by merocrine and apocrine secretions in some Clara cells [18]. On the other hand, basal cells, which are small polyhedral cells on the basement membrane, were few and distributed throughout the bronchus and bronchiole and adhered to neighboring cells by desmosomes. The nucleus occupied a large portion of the cells with tonofilaments having a few organella.

\section{Goblet Cell Metaplasia from Clara and Ciliated Cells}

In this section goblet cell metaplasia from mainly Clara and ciliated cells will be introduced. Epithelial cell hyperplasia and metaplasia are common consequences of airway inflammation and may be associated with protective as well as pathogenic outcomes. Metaplasia implies a change in cell phenotype, while hyperplasia indicates cell proliferation as the mechanism for the increase in goblet cell numbers. Clara cells have a capacity to differentiate into goblet cells [19]. In tracheal epithelium in a rat model that epidermal growth factor receptor (EGFR) activation may promote selective cell differentiation (not proliferation), from Clara cells to goblet cells [20,21]. Nadel [21] hypothesized that the mechanism of EGFR expression and activation as follows (Figure 2A). Stimulation of airway epithelial cells with tumor necrosis factor (TNF)- $\alpha$ causes EGFR expression and EGFR ligandsbind to EGFR, resulting in EGFR tyrosine phosphorylation and a subsequent downstream cascade, which causes mucin gene and protein expression. Human airway epithelial cells stimulated with the EGFR ligands such as transforming growth factor- $\alpha$ (TGF- $\alpha$ ) and EGF, develop a mucous phenotype [21,22]. Intratracheal administration of these ligands after TNF- $\alpha$-induced up-regulation of EGFR on airway epithelial cell in rats resulted in mucous metaplasia [22]. EGFR activation is required for inducing mucous metaplasia in animal models and for up-regulation of mucin expression in human airway epithelial cells in response to allergens, viruses, neutrophils, and cigarette smoke in human with asthma [22-25]. This chronic switch in epithelial behavior exhibits genetic susceptibility and depends on persistent activation of EGFR (also designated ErbB1 and HER1) signaling to PI3K that prevents apoptosis of ciliated cells, and IL-13 signaling that promotes transdifferentiation of ciliated to goblet cells, 


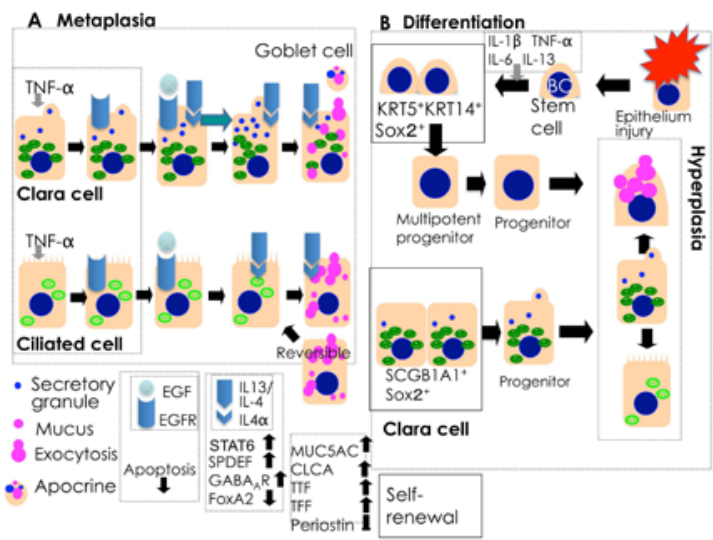

Figure 2: Nadel [21] reviewed that stimulation of airway epithelial cells with TNF- $\alpha$ causes EGFR expression. Curran and Cohn [33] proposed the hypothesis that goblet cell differentiation requires two signals (A). The hypothesis: Signal 1 activates EGFR on the epithelial cells (Clara and ciliated cells), leading to inhibition of epithelial cell apoptosis. Epithelial cells that survive have the potential to become goblet cells if provided with Signal 2, IL-13 binding to its receptor. Upon IL-13R and Stat6 activation, epithelial cells show an increase in SPDEF and reduced FoxA2 expression. GABA $R$ responsiveness is required for goblet cell metaplasia, which is induced by IL13. After expression of MUC5AC, CLCA and TIFF, cells lose the features of epithelial cells from which they arose and become goblet cells that produce mucins. Also reversible changes from established goblet cell metablasia to ciliated cells may occur. Hypothetical differentiation and hyperplasia depending on tentative working model for the self-renewal and differentiation of basal stem cells in mouse and human airways proposed by Rock et al. [82] are shown in (B) with some modification. A subset of BCs in the normal airway expresses both KRT5 and KRT14. BCs self-renew over the long term and generate ciliated, secretory cells and goblet cells. On the other hand, Clara cells expressing SCGB1A $1^{+}$, may be one of stem cells, can proliferate and give rise to goblet, Clara and ciliated cells via progenitor cells. Also Sox2 is required for proliferation and differentiation of Clara and basal cells. Concequently, metaplasia from Clara cell to goblet cells and ciliated cells may occur after differentiation.

leading to increased expression of EGFR on ciliated andgoblet cells $[26,27]$. IL-13 can directly drive mucin gene expression in airway epithelial cells $[27,28]$. The downstream events connecting IL-13R activation to mucin gene expression are incompletely defined, but preliminary work with inhibitors indicates requirements for MEK (mitogen-activated protein kinase)/ERK (extracellular signal-regulated kinase), p38 MAPK (mitogen-activated protein kinase), and PI3K (phosphatidylinositol 3-kinase) activation, at least, in vitro [29]. These effects appear to develop in concert with calcium-activated chloride conductance to promote fluid secretion and consequent mucociliary clearance [30]. This function may be connected to expression of a calcium-activated chloride channel (CaCC1) that is specific for goblet cells [31]. Thus, IL-13 appears to directly stimulate epithelial mucin formation, but the type of target epithelial cells and the cellular process for mucous cell differentiation remain less certain. Also a transition of Clara to goblet cells in human disease is reported [32]

Curran and Cohn [33] proposed a two-step model in metaplasia of goblet cells. IL-13 induces not only MUC5AC gene expression leading to mucin synthesis, a defining characteristic of the goblet cell phenotype, but also induces other genes, some of which are important for goblet cell function, including the genes for the $\mathrm{CaCC} 1$, and the trefoil factor family (TFF), which will be mentioned later $[34,35]$. In addition, Young et al. [36] indicated that up-regulated Muc5AC expression is the central event in goblet cell metaplasia in antigen-challenged mice. A number of transcription factors that are important in lung development have been identified in the airway epithelium and have been shown to play key roles in mucous metaplasia. The forkhead box transcription factor FOXA2, regulates genes that are involved in lung maturation and epithelial cell differentiation. FOXA2 inhibits MUC5AC gene expression [37]. Allergen challenge or transgenic overexpression of IL-4 or IL-13 in mice resulted in pulmonary inflammation and goblet cell metaplasia, which was associated with significant inhibition of FOXa2 expression in the airway epithelium [38]. Thus, FOXA2 is required for maintenance of normal differentiation of the airway epithelium and inhibition of FOXA2 appears to be an important early step in the initiation of mucous metaplasia.

Thyroid transcription factor 1 (TTF-1) plays a critical role in peripheral lung morphogenesis and is an important regulator of genes involved in many biological functions in the lung, including host defense, fluid balance, surfactant homeostasis, lung vasculogenesis, and epithelial cell differentiation [39]. ETS transcription factor (SPDEF), an epithelial specific transcription factor that is markedly induced by a phophorylation mutant of TTF-1, was shown to be constitutively expressed in proximal airway epithelial cells and submucosal glands in the adult mouse lung [40]. Transgenic overexpression of SPDEF in the murine airway epithelium caused spontaneous mucous metaplasia. SPDEF appeared to interact with TTF-1 to have a synergistic effect on the promoters of a number of genes but had no direct effect on the MUC5AC gene promoter. SPDEF overexpression did, however, result in down-regulation of FOXA2 expression. SPDEF has been shown to be both necessary and sufficient for induction of a transcriptional program that results in goblet cell differentiation [41]. Expression of a member of the Clca gene family (i.e., calcium-activated chloride channel-3; mClca3) with the development of mucous cell metaplasia but not airway hyperreactivity [42] has been reported. The $5^{\prime}$-regulatory region of the $\mathrm{mClca} 3$ gene contains a putative binding site for the Stat6 transcription factor that mediates IL-13R signal transduction and that IL-13 stimulates mClca3 (and $\mathrm{mClca} 5$ ) gene expression in cultured airway epithelial cells [43]. The mouse system appears to be directly relevant to human airway disease because the human homologs for mouse mClca3 and mClca5, human calcium-activated chloride channel-1(hCLCA1) and hCLCA2, are both overexpressed in airway tissue of subjects with asthma [43,44]. mCLCA-3(gob-5)/human CLCA- 1 acts as a downstream molecule of Th2 cytokines, IL-4/IL-9/IL13 signals, playing an important role in mucus production andpendrin, an anion transporter, is induced by IL-13 and causes mucus production in airway epithelial cells [45].

Epidermal growth factor (EGF) and trefoil factor family (TFF) peptides support synergistically several processes of goblet cell metaplasia [46]. TFFs are well known particularly for their key role in mucosal reconstruction and TFFs also support mucosal differentiation processes. Particularly the latter process reflects the plasticity of the airway epithelium and causes intense airway remodeling. Goblet cells are derived, at least in part, from Clara cells, which trans-differentiate from a serous into a mucous phenotype. Using a murine asthma model it was shown that trans-differentiating Clara cells specifically express TFF1, which is stored in a specific subset of secretory granules [47] These points to a role for TFF1 as an autocrine factor for the transdifferentiation of Clara cells toward goblet cells [47]. It is demonstrated that induction of TFF3 synthesis was shown with differentiation in vivo humanized tracheal xenograft and in vitro air-liquid interface culture models. Furthermore, exogenous TFF3 promoted differentiation of ciliated cells in an EGFR-dependent manner. Taken together, both studies imply that TFFs may play key roles for various differentiation processes of the airways [46]. 


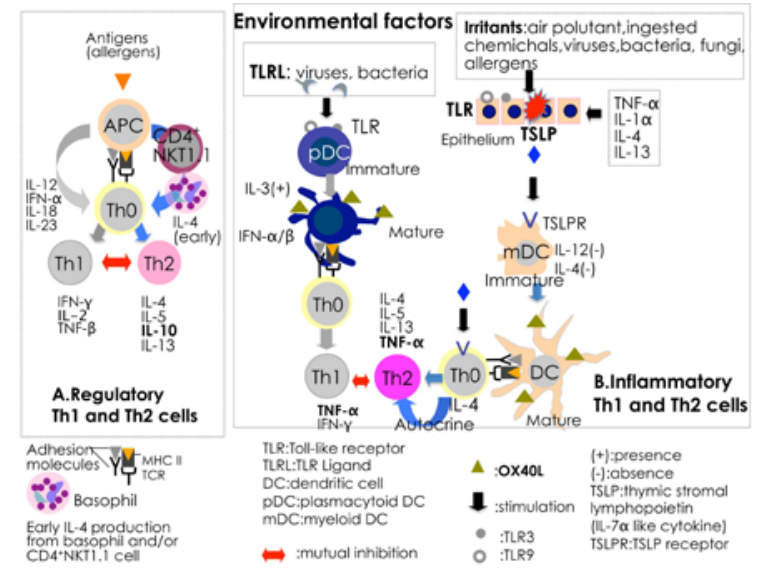

Figure 3: Hypothetical responses of Th1 and Th2 cells in regulatory (A: see detail in the section of goblet cell metaphase from Clara and ciliated cells) and inflammatory (B) subtypes proposed by Liu [107]. IL-4 and IL-12 are classic Th2 cell-polarizing and Th1 cell-polarizing factors, respectively. OX40L, which contributes to the differentiation, proliferation and actibation of $\mathrm{T}$ cells, from DCs together with IL-4 promotes TNF- $\alpha$ but inhibits IL-10 production from inflammatory Th2 cells or inflammatory Th1 cells induced by OX40L together with IFNa/ $\beta$ from DCs. Injury of epithelial cells or epithelial cell stimulated with environmental factors (TLRLs) reacting with TLR on epithelium trigger to produce TSLP from mucosal epithelium, leading to expression of TSLPR on DCs. TSLP initiates the innate phase of allergic immune responses by activating immature DCs. TSLP-activated mDCs lead to the adaptive phase of allergic immune responses. TSLP-activated DCs expressing OX40L, which induce the inflammatory Th2 cells. In addition, TSLP was shown to be able to directly act on naïve $\mathrm{CD} 4^{+} \mathrm{T}$ (Th0) cells to promote Th2 differentiation and/ or IL-4 secretionin vivo and in vitro. On the other hand, DCs stimulated with TLRLs produce IFNa/ $\beta$ in the innate phase, leading to the development of the adaptive phase of Th1 responses.

$\gamma$-Aminobutyric acid (GABA) has also been identified as an important regulator of goblet cell metaplasia. The GABAA receptor $\left(\mathrm{GABA}_{\mathrm{A}} \mathrm{R}\right)$ is a pentameric chloride channel that mediates inhibitory signals in the brain [48]. GABA $R$ and GABA synthetic enzymes were also shown to be expressed in airway epithelial cells [48]. In vitro studies demonstrated that GABA enhanced airway epithelial cell proliferation and increased mucin production and secretion. Furthermore, IL-13 induces GABA $\mathrm{R}$ expression in airway epithelial cells both in vitro and in vivo. Thus, the airway epithelial GABAergic system promotes mucous metaplasia by effects that are downstream of IL-13.CLCAs also appear to control airway mucus. These effects of CLCA are downstream of Th2 cytokines and are Stat6 dependent. CLCA1 expression is increased in human inflammatory airway diseases and is associated with mucus production. Mucus hypersecretion is induced by airway inflammation and is caused by a variety of different stimuli associated with different cytokine expression profiles. Asthma is believed to be caused, in part, by allergen-specific Th2 cells that produce the cytokines such as IL-4, IL-5, IL-9, IL-10, and IL-13 [49] (Classic or regulatory Th2 cell response: Figure 3A). Many studies into the mechanisms of mucous metaplasia have thus focused on mouse models of Th2 cellmediated airway inflammation. Chronic overexpression of individual Th2 cytokines has been achieved using lung-specific promoters. Overexpresser transgenic mice with the Clara cell $10-\mathrm{kD}$ (CC10) promoter driving the Th2 cytokines IL-4, IL-5, IL-9, or IL-13 exhibited the characteristic features of allergic airway inflammation, including eosinophilia, mast cell activation, and mucus overproduction [50]. IL-4 and IL-13 share a common receptor subunit ( IL-4Ra) and blockade of IL-4/IL-13 signaling, through knockout of IL-4Ra1, resulted in failure of IL-13 or Th2 cells to induce mucous metaplasia [51,52]. Mucous metaplasia was abolished in transgenic mice overexpressing IL-9 when IL-13 signaling was inhibited through STAT6 deletion; and in situ hybridization indicated that airway epithelial cells were the source of IL-13 [53]. These studies showed that IL-13 is necessary for Th2mediated airway inflammation in mice. Furthermore, IL-13 is highly potent and very low levels can effectively promote mucous metaplasia [53]. IL-13 appears to act via direct effects on airway epithelial cells. Downstream of epithelial cell signaling events is mediated by STAT6dependent de novo protein synthesis, resulting in activation of $\mathrm{p} 38$ mitogen-activated protein kinase, which appears to be essential for IL13-induced mucous metaplasia [54]. Studies in airway epithelial cell cultures using specific inhibitors also suggest that phosphatidylinositol 3 kinase (PI3K) is required for IL-13-induced mucin gene expression and mucus staining [29].

Mucous metaplasia does not occur in all immune responses, particularly those rich in IFN- $\gamma$ by mutual inhibitory effects between Th1 and Th2 cells (Figure 3). Th1 cell-induced airway inflammation did not stimulate mucous metaplasia [55]. IFN- $\gamma$ inhibits mucous cell transition, even in the presence of high levels of Th2 cytokines (Cohn et al. [49], unpublished data). Thus, IFN- $\gamma$ may inhibit airway epithelial mucus by blocking steps required for IL-13 to act, such as inhibiting EGFR actions to promote cell survival. Alternatively, IFN- $\gamma$ may act by inhibiting downstream effects of IL-13. The molecular mechanisms by which IFN- $\gamma$ inhibits mucus are still being defined. In cultured human airway epithelial cells, IFN- $\gamma$ was shown to inhibit IL-4-induced STAT6 phosphorylation and to reduce the expression of IL-4 target genes [56]. Furthermore, IFN- $\gamma$ also induced expression of suppressor of cytokine signaling-1 and IL-13R 2 2, inhibitors of IL-4/ IL-13 signaling, as well as increasing the decay of IL-4 target gene mRNA. Thus, IFN- $\gamma$ may inhibit Th2-induced responses in epithelial cells through a number of pathways. IFN- $\gamma$ also promotes resolution of allergen-induced mucous metaplasia by stimulating airway epithelial apoptosis via Bax- and caspase-dependent mechanisms [57]. IFN- $\gamma$ induced cell death involves STAT1-dependent translocation of Bax to the endoplasmic reticulum [58]. Sehra et al. reported [59] that periostin, a $90-\mathrm{kDa}$ member of the fasciclin-containing family and functions as part of the extracellular matrix, is expressed in a variety of tissues and expression is increased in airway epithelial cells from asthmatic patients as follows. Sensitization and challenge of periostin-deficient mice with OVA resulted in increased peripheral Th2 responses. In the lungs, periostin deficiency resulted in increased airway resistance and significantly enhanced mucus production by goblet cells concomitant with increased expression of Gob5 and Muc5ac compared with wild type littermates. Periostin also inhibited the expression of Gob5 involved in the regulation of mucus production, in primary murine airway epithelial cells, suggesting that periostin may be part of a negative-feedback loop regulating allergic inflammation.

Morphorogically increased S.G., identical to Clara cell secretory (specific) protein (CCSP), are seen in the late allergic asthmatic model mice [18]. Clara cells having increased S.G. (CCSP) without mucus suggest that the significance of increased CCSP in allergic status may be the result of protection against injurious agents in environmental air primarily [32]. Thereafter, those cells with mucus may become goblet cells and there are two structural discharge of mucin such as secretion of mucins of membrane-bound mucins and apocrine fasion [18]. In addition, the loss of cristae and mitochondrial swelling has been found in an asthmatic mouse model [60]. Moreover increased CCSP will be induced by IL-13 [20] and IL-13 was shown to induce MUC5AC expression via a mechanism requiring a secondary TGF- $\beta 2 / S M A D-$ mediated signal in airway epithelial cell cultures [61]. These suggest 
that CCSP may be related with goblet metaplasia. Thus, allergeninduced goblet cell metaplasia from CCSP-positive Clara cells contains mucous granules in mice $[18,62,16]$. In fact, significant levels of CCSP-driven recombination can be found in ciliated and nonciliated airway epithelial cells [63]. CCSP and $\beta$-tubulin co-localization with MUC5AC in mice and in humans suggest that ciliated cells and Clara cells may each demonstrate sufficient plasticity to contribute to goblet cell metaplasia [63]. However, the relationship between increased S.G. and mucus production in Clara cells is not always identical [18]. Thus further study is needed to clarify this point. Alternatively hypoxiainducible factor-1 (HIF-1) is a transcriptional activator that mediates gene expression in response to cellular oxygen concentrations [64]. HIF-1 is known to contain a conserved STAT6 motif in its promoter, and binding of HIF- 1 to the MUC5AC promoter is induced by IL-13 and EGF stimulation including that HIF- $1 \alpha$ is activated in antigeninduced airway disease through PI3K- $\delta$ signaling [65]. Goblet-cell metaplasia may occur in the intrapulmonary airway in a mouse model of asthma. A few fine granules, which correspond to PAS-positive granules stained with TB in semi-thin sections, are observed in the apical site of the non-ciliated epithelium (Clara cells) in normal mice. Thus most goblet-cell metaplasia in the bronchus and bronchiole of inflamed mucosa may be derived from Clara cells. In re-population of airway after injury, a morphological derivative of the Clara cell, referred to as a type-A cells, lack the differentiated ultrastructural features, such as s.e.r. and S.G., that are characteristic of mature Clara cells [41] may be immature Clara cells (designate here as iClara cellinstead of type-A Clara cell). In asthma animal model, iClara cells and/or goblet cells may not be derived from neuroendocrine cells, which are only located in terminal bronchioles, since goblet-cell metaplasia was observed in bronchus rather than terminal bronchiole [18,66-68]. On the other hand, hyperplastic goblet cells at distal sites, at least in part, are considered to be metaplasia from Clara cells in human asthma [69]. In addition, it has been reported that IL-9 in airway injury repair resulted in goblet-cell hyperplasia in murine models of asthma [17]. Ciliated cells can be converted to goblet cells in primary cell culture from Guinea pig tracheal epithelium $[26,70]$ as described above and that metaplasia is the dominant mechanism mediating the expansion in goblet cell numbers in human asthma [70].

\section{Goblet Cell Differentiation and Hyperplasia from Stem Cell}

In this section, goblet cell hyperplasia after differentiation (regeneration) from proliferated progenitor cells includingbasal cells (BCs) will be introduced. The increase in hypertrophic goblet cell numbers in the respiratory epithelium during airway inflammation has been described both as mucous metaplasia and as goblet cell hyperplasia. In human airways, a detailed analysis of the epithelial transition to a mucus-secreting phenotype has not been undertaken. In a murine model of asthma, there was a dramatic increase in goblet cell number after sensitization and allergen challenge, while the number of epithelial cells per unit surface area of the basal lamina remained constant and Clara cells were undergoing metaplasia to mucous cells [62] as mentioned already. Thus, these seem to be two types of increased goblet cells such as the metaplasia rather than hyperplasia and so called goblet cell hyperplasia explained below.

In the normal human airway epithelium, a tight balance between $\mathrm{BC}$ self-renewal and generation of physiologically appropriate proportions of secretory and ciliated cells is required [71]. This may be mediated by the behaviors of stem cells and potential multipotent intermediate progenitors. Alternatively the changes might result from altered paracrine signaling within the dynamic and complex BCs niche. In either case, hyperproliferating BCs secrete cytokines, such as IL-1, that promote airway wall fibrosis [71]. It is believed that Clara cells' change their phenotype to either express mucins or chitinases, depending on their position in the airways [38], and there seems to be direct, reversible conversion of Clara cells into goblet cells, a change that is correlated with expression of SPDEF and downregulation of another transcription factor, FOXA2 [41], where SCGB1A1+ Clara cells (Clara cells expressing secretoglobin, family $1 \mathrm{~A}$, member 1 ; also known as uteroglobin)can self-renew over the long term and they may bebronchioalveolar stem cells (BASCs) in the trachea, bronchioles and alveoli, which are maintained by distinct populations of epithelial progenitor cells [72]. Mucous metaplasia and the expression of SPDEF are observed in human small airways, in which BCs are abundant [72]. It will be important to model this condition in proximal mouse airways in which BCs are found. It is likely that cytokines such as IL13 , IL-6, IL-1 $\beta$ and TNFa directly or indirectly influence the fate of BCs and their immediate progeny $[72,73,15]$. In support of this idea, treating human air-liquid interface airway epithelial cultures (probably initiated mainly with BCs) with exogenous Notch ligand or IL-13 resulted in a drastic increase in the number of mucus-producing goblet cells [73]. Upstream events include a new immune axis for growth factor and cytokine production and downstream events that include ciliated epithelial cell survival and transdifferentiation to mucous cells as well as expression of CLCA genes [15].

Rock et al. [15] reviewed that BCs are a population of multipotent stem cells that drives both homeostasis of the normal epithelium and its orderly regeneration after injury. Disruption of the normal balance between $\mathrm{BC}$ proliferation and differentiation can lead, at two extremes, to $\mathrm{BC}$ hyperplasia or epithelial hypoplasia. Changes in the lineage choice of BCs or their undifferentiated daughters might contribute to the mucous cell hyperplasia, metaplasia or squamous metaplasia seen in many respiratory disorders. BCs are important in the initiation and progression of airway disease [15]. Among cytoskeletal proteins, cytokeratins 5 and 14 (KRT5 and KRT14, respectively) are typically expressed in BCs. There is differential expression of these proteins in airway BCs. At steady state, most mouse tracheal BCs express KRT5, whereas only a subset expresses KRT14 [82]. Mouse BCs generated lineage-labeled basal, ciliated and Clara cells [15]. However, during repair after naphthalene-induced injury, KRT14 expression is upregulated in the $\mathrm{BC}$ population $[74,75]$. KRT14 also has a more restricted expression pattern than KRT5 in the human airway, but is expressed in $\mathrm{TRP} 3^{+} \mathrm{BC}$ in regions of squamous metaplasia [15]. Thus they pointed out that the functional significance of differential cytokeratin expression at steady state after injury and pathological changes of remodeling [15].

In the uppermost mouse trachea, BCs form a mostly continuous monolayer, but they are found in clusters or as individual cells more distally [76]. In the larger human airways, BCs also form a continuous monolayer but similarly become distributed into clusters and individual cells in the small terminal bronchioles [76]. In both the mouse and human, BCs form desmosomal contacts with neighboring columnar cells and are anchored to the basal lamina via hemi-desmosomes and other highly expressed adhesion molecules. The subjacent lamina propria contains mesenchymal cells, such as fibroblasts and immune cells (e.g. macrophages) [15] and dendritic cells (DCs) [77]. In addition, the mouse trachea and human intrapulmonary airways are richly endowed with blood vessels and nerves, which enter between the cartilage rings and encircle the airway $[15,78]$. Systemic blood vessels of the bronchial circulation supply many generations of 
intrapulmonary airways in humans, whereas in the mouse, these vessels do not penetrate beyond the mainstem bronchi, even after pathological stimulation of angiogenesis [79]. However, despite notable differences between mouse and human airways, BCs of the pseudostratified airway epithelia in both species are molecularly and histologically very similar. By definition, a stem cell can self-renew and generate differentiated progeny of one or more cell types. Relevant studies have been reviewed that BCs gave rise to both ciliated and Clara cells. By contrast, lineagelabeledClara cells expressing SCGB1 $\mathrm{Al}^{+}$cellsin the trachea proliferate and generate ciliated cells but a population was replaced over time by unlabeled progenitor cells, presumably BCs [12]. This suggests that, in airway epithelia containing BCs, the Clara cells do not function as stem cells over the long term under normal conditions. On the other hand, Randell [80] reviewed that both BCs and nonciliated columnar epithelial cells of the rodent trachea proliferate in the steady state and in response to injury $[81,82]$. BCs can regenerate a fully differentiated mucociliary epithelium when seeded in denuded tracheas (host tracheas that have been stripped of their epithelium) and transplanted subcutaneously in nude rats $[83,84]$. Alternatively, some lumenal cells might have the capacity to regenerate BCs under these conditions. Preliminary evidence that mouse SCGB1A1 ${ }^{+}$cells can generate both self-renew and generate ciliated cells after epithelial injury in in vivo lineage-tracing studies [72]. Individual sorted $\mathrm{TRP} 63^{+} \mathrm{NGFR}^{+} \mathrm{KRT}^{+} \mathrm{BCs}$ from the mouse trachea self-renew give rise to clonal 'tracheospheres' containing both ciliated and secretory cells, and NGFR- lumenal cells do not form tracheospheres. Among human tracheo-bronchial epithelial cell types, $\mathrm{TRP} 63^{+} \mathrm{NGFR}^{+} \mathrm{BCs}$ demonstrating their capacity to self-renew generate ciliated and secretory cells [15]. Also, human TRP63 ${ }^{+} \mathrm{KRT}^{+}$ $\mathrm{BCs}$ are isolated from normal human airways [85]. These cells, estimated to constitute $0.01 \%$ of the total airway epithelium, proliferate and generate ciliated and secretory cells. This progenitor might still proliferate (in which case it would be considered a transit-amplifying cell) and give rise to either ciliated or secretory cells.

Tompkins et al. reported [86] that Sox2, which is a member of the SRY-high mobility box transcription factor family, is expressed in epithelial cells of the foregut, including pharynx, esophagus, trachea, bronchi, and bronchioles, but is excluded from the peripheral and alveolar regions of the lung physically, interacted with Smad3 and inhibited TGF- $\beta 1 /$ Smad3-mediated transcriptional activity in vitro, a pathway that negatively regulates proliferation. Also Sox 2 is required for proliferation and differentiation of Clara and basal cells that serve as the progenitor cells from which Clara, ciliated, and goblet cells are derived. The existence of such an early progenitor population is still hypothetical, but these cells might correspond to some of the 'indeterminate' or 'intermediate' epithelial cells that have been described in human airways [87].

\section{Environmental Factors in Driving Goblet Cell Responses}

In this section, interaction among DCs, respiratory epithelium and environmental factors being responsible for goblet cell responses in the development of inflammatory Th2 cells (Figure 3B) in airway allergy will be introduced [88] other than regulatory Th2 cells, which are already mentioned. DCs are the professional antigen presenting cells (APC) that have the capacity to present antigen to naive-T (Th0) cells and T-effector (Te) cells and also DCs have an important role in the immunological outcome of the disease [89]. Circulating immature DCs were found to represent a small leukocyte population that produces large amounts of IFN- $\alpha$ in the presence of certain viruses [90]. Two major types of DCs have been characterized in humans: the CD11 $\mathrm{c}^{+} \mathrm{CD} 123$ myeloid dendric cells ( $\mathrm{mDCs}$ ), for which there are several subtypes, and the $\mathrm{CD} 11 \mathrm{c}^{-} \mathrm{CD} 123^{+}$(IL-3Ra-chain) lymphoid cells known as the plasmacytoid DCs (pDCs) [91,92]. mDCs with CD11c ${ }^{+}$DCs, a very potent antigen-presenting cell (APC) type, for their capacity to induce allergen-dependent activation of Th2 memory cells [93]. Tuma et al. [94] demonstrated the presence of mDCs in nasalmucosa with and without allergies. Jahnsen et al. [95] reported that pDCs, most likely has an important role both in innate defense against pathogens and as APCs in the adaptive immune system. This cell type exists in bone marrow, blood, organized lymphoid tissues and at effector sites with direct antigens (allergens) exposure such as the mucosae.In addition, pDCs are identified by their high expression of CD123, together with CD45RA andare present in low and variable numbers in normal nasal mucosa (including probably bronchial mucosa) but increased dramatically during the nasal (and also probably bronchial) allergic reaction [95].

DCs play a critical role in directing the types of T-cell responses, including Th1, Th2, and Th17. The ability of DCs to induce either Th1 or Th2 responses appears to be dictated by the type of signals that the DCs received at an immature stage [96-98]. In addition, bronchial epithelial cells, fibroblasts, smooth muscle cells, and mast cells have the potential to produce TSLP in human $[96,99]$. Wang et al. [100] reviewed the interaction between ligands and epithelial cells as follows, since exposure of the airway inflammatory stimuli through activation of epithelial Toll-like receptor (TLR)s to provide an important link between innate immunity and allergic disease. Additionally, airway epithelial cells can act as inflammatory promoters capable of directing DCs towards a Th2 response. TSLP production can be induced in airway epithelial cells by ligands that activate TLR2, TLR3, TLR8 and TLR9 to release TSLP protein, and TLR8 and TLR9 to stimulate TSLP gene transcription through NF-kB activation [100]. Ligands (TLRL) capable of activating these TLRs include bacterial lipoteichoic acid and peptidoglycans from bacteria (TLR2), single stranded (TLR8) and double-stranded (TLR3) viral RNA, and CpG DNA motifs in both viruses and bacteria (TLR9).TLR activation can also be initiated by other factors such as viruses, dustsand chemicals [100]. TSLP activated immature mDCs rapidly express TSLP receptor (TSLPR) and DCs undergo maturation in response to TSLP [96]. Unlike OX40L and TLR ligands, TSLP does not stimulate mDCs to produce the Th1-polarizing cytokines such as IL-12 or the proinflammatory cytokines (e.g. TNF- $\alpha$, IL-1 $\beta$, and IL-6) [96]. TSLP causes mDCs to produce large amounts of the chemokines such as IL-8 and eotaxin-2, which attract neutrophils and eosinophils, as well as thymus and activation regulated chemokine (TARC) and macrophage-derived chemokine (MDC), which attract Th2 cells [96,101]. Liu [96] suggests that the inability of TSLP to induce the production of Th1-polarizing cytokines by mDCs is one of the most important features of TSLP-activated DCs, although the molecular mechanisms underlying TSLP's ability to promote mDC maturation without inducing the production of Th1-polarizing cytokines are unknown. OX40L on DCs represents the original Th2-polarizing signal from TSLP-DCs, and IL-4 represents a critical autocrine stabilizer and enhancer of the developing Th2 cells. Thus, OX40L and IL- 4 work synergistically and sequentially in driving Th2 responses in $\mathrm{T}$ cells $[101,102]$. Also, TSLP costimulates mast cells to produce inflammatory and Th2 cytokines. Also, TSLP is highly expressed by skin keratinocytes and airway epithelial cells during allergic inflammation. Although the triggering mechanims of TSLP production by allergen or viral and bacterial infection are not well known, it appears to involve STAT5 activation, independent of the classic NF- $\mathrm{B}$ and MyD88 signaling pathways. In the presence of IL-12, OX40L signaling instead promotes the development of Th1 cells. Liu [96] proposed the subdivision of Th2 


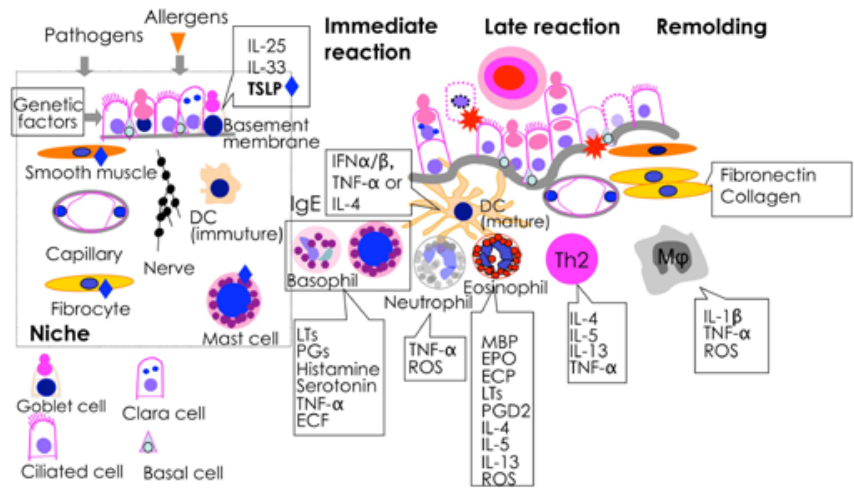

Figure 4: Production of TSLP and cumulative effects in the development of asthma, leading to goblet cell responses and epithelium damage. Epithelial cells interacting with environmental factors (e.g. pathogens and allergens) will lead to the production of TSLP, which trigger the development of asthma under the influence of susceptible gene. In these processes components of niche (microenvironments) may contribute to the development of asthma together with Th2 cells and other inflammatory cells, which produce several kinds of mediators. These mediators recruit or activate various types of inflammatory cells, leading to goblet cell responses. In turn, these inflammatory cells release various reactive oxygen spiesies (ROS), such as superoxide anion, hydroxyl radical, hydrogen peroxide and nitric oxide. As a result, these mediators induce goblet cell responses and damage surrounding epithelial cells in the airway mucosa.

cells into inflammatory Th2 cells that produce high levels of TNF- $a$ but little IL-10, and conventional Th2 cells that produce little TNF-abut high levels of IL-10. If that is the case, these mechanisms may operate in allergic rhinitis, although it is not well understood in nasal epithelial cells.

\section{Future Direction}

The mechanisms of goblet cell metaplasia, differentiation and hyperplasia are clarified by mainly in vitro study [103]. However, in vitro cultures do not always reflect physiologic conditions in vivo $[104,105]$. The pathological changes in asthma affect the epithelium morphology and function. The constitute of bronchial mucosa such as ciliated epithelial cells, goblet cells, basal cells, basement membrane,fibroblast,smooth muscle, capillary, DC and bronchial gland (niche) may contribute to the development of asthma (Figure 4). The interaction of epithelial cells and underlying mesenchyme including inflammatory cell responses may affect or determine the fate of epithelial cells. Tang [106] pointed out that BCs proliferation and differentiation in vivo is still not known. Thus, it will be important to understand the difference between in vitro and in vivo, and how they are coordinated and how microenvironmental signals are integrated in metaplasia, hyperplasia and differentiation of goblet cells to direct homeostasis, repair and pathological remodeling of airways. Moreover, we have to remind that the data obtained from model mouseare not simply applicable for human with asthma, since there are some species differences such as composition of epithelial cells and their function.

TSLP play a key role in goblet cell responses as the result of the development of asthma. TSLP is a cytokine produced by the skin and airway epithelium stimulated with environmental factors including TLRL that is capable of directing DCs towards a inflammatory Th2 response, thereby providing an essential link between epithelial cell activation and allergic-type inflammation. In addition, TSLP can interact directly with mast cells to initiate Th2 cytokine production to also provide a non- $\mathrm{T}$ cell route to mediate its pro-allergic effects.
Holgate [107] pointed out thatinduction of TSLP production occurs through the activation of epithelial TLRL to provide an important new link between innate immunity and allergic disease.Moreover, it has been demonstrated that TSLP diverted airway tolerance against ovalbumin to Th2 sensitization and inhibited the generation of OVAspecific Foxp $3^{+}$regulatory T cells [108]. Therefore, TSLP and OX40 ligand may represent important targets for intervention of the initiation of allergic inflammatory responses [107].

The asthmatic epithelium is known to be abnormally susceptible to apoptosis induced by oxidants, possibly due to a lack of endogenous protective factors $[109,110]$. Moreover, there is some evidence indicating the possible involvement of mitochondrial DNA defects in the etiology of asthma [110-112]. The recruitment of Th2 cells to the airway and the activation of those cells may produce ROS leading to mitochondrial damage and dysfunction by activated inflammatory cells $[60,113,114]$. Several oxidative stress studies revealed that endogenous antioxidant enzymes were decreased in the peripheral tissues of asthmatic adult patients relative to the control subjects, indicating that mitochondrial dysfunction and oxidative stress is present in asthmatic adults [115]. However the relation of those changes and mucus production in vitro and in vivo events [105] istotally unknown.Thus, additional work is needed to fully answer this questionsfor better therapy in the control of mucus hypersecretion.

\section{Acknowledgements}

The author acknowledges reusing figure 9 (corresponding to Figure $1 \mathrm{~B}$ in the present manuscript) from (Hayashi T, Ishii A, Nakai S, Hasegawa K (2004) Ultrastructure of goblet-cell metaplasia from Clara cell in the late asthmatic airway inflammation in a mouse model of asthma. Virchow Archiv 444: 66-73) is permitted by Special Licensing Department of springer (Date: Äb027-07-2012). The author also appreciates to reuse figure 1 (corresponding to figure 3 in the present manuscript) from (Hayashi T (2012) Molecular mechanisms in allergic rhinitis: modulation by microbe. In: Advancesin Medicine and Biology 40: 59-90. (ed., LV Berhard) ISBN: 978-1-62100-421-9. Nova Sci Pub) is perimited by Nova Science Publishers, Inc (Date: 17-10-2012)

\section{References}

1. Reddy PH (2011) Mitochondrial Dysfunction and Oxidative Stress in Asthma: Implications for Mitochondria-Targeted Antioxidant Therapeutics. Pharmaceuticals 4: 429-456.

2. Hayashi T (2011) Immunopathogenesis of distant manifestation in effector phase after local airway allergy. Res Trends 12: 67-76.

3. Tang ML, Wilson JW, Stewart AG, Royce SG (2006) Airway remodelling in asthma: current understanding and implications for future therapies. Pharmacol Ther 112: 474-488

4. Shimura S, Andoh Y, Haraguchi M, Shirato K (1996) Continuity of airway goblet cells and intraluminal mucus in the airways of patients with bronchial asthma. Eur Respir J 9: 1395-1401.

5. Aikawa T, Shimura S, Sasaki H, Ebina M, Takishima T (1992) Marked goblet cell hyperplasia with mucus accumulation in the airways of patients who died of severe acute asthma attack. Chest 101: 916-921.

6. Voynow JA, Gendler SJ, Rose MC (2006) Regulation of mucin genes in chronic inflammatory airway diseases. Am J Respir Cell Mol Biol 34: 661-665.

7. Rose MC, Voynow JA (2006) Respiratory tract mucin genes and mucin glycoproteins in health and disease. Physiol Rev 86: 245-278.

8. Carraway KL, Perez A, Idris N, Jepson S, Arango M, et al. (2002) Muc4/ sialomucin complex, the intramembrane ErbB2 ligand, in cancer and epithelia: to protect and to survive. Prog Nucleic Acid Res Mol Biol 71: 149-185.

9. Li Y, Bharti A, Chen D, Gong J, Kufe D (1998) Interaction of glycogen synthase kinase 3beta with the DF3/MUC1 carcinoma-associated antigen and betacatenin. Mol Cell Biol 18: 7216-7224.

10. Rose MC, Voynow JA (2006) Respiratory tract mucin genes and mucin glycoproteins in health and disease. Physiol Rev 86: 245-278. 
Citation: Hayashi T (2012) Molecular Mechanisms of Metaplasia, Differentiation and Hyperplasia of Goblet Cellin Allergic Asthma. J Aller Ther 3:121. doi:10.4172/2155-6121.1000121

Page 8 of 10

11. Perez-Vilar J (2007) Mucin granule intraluminal organization. Am J Respir Cell Mol Biol 36: 183-190

12. Martin LD, Rochelle LG, Fischer BM, Krunkosky TM, Adler KB (1997) Airway epithelium as an effector of inflammation: molecular regulation of secondary mediators. Eur Respir J 10: 2139-2146.

13. Li Y, Martin LD, Spizz G, Adler KB (2001) MARCKS protein is a key molecule regulating mucin secretion by human airway epithelial cells in vitro. J Biol Chem 276: 40982-40990

14. Singer M, Martin LD, Vargaftig BB, Park J, Gruber AD, et al. (2004) A MARCKSrelated peptide blocks mucus hypersecretion in a mouse model of asthma. Nat Med 10: 193-196.

15. Rock JR, Randell SH, Hogan BL (2010) Airway basal stem cells: a perspective on their roles in epithelial homeostasis and remodeling. Dis Model Mech 3 : 545-556.

16. Evans CM, Williams OW, Tuvim MJ, Nigam R, Mixides GP, et al. (2004) Mucin is produced by clara cells in the proximal airways of antigen-challenged mice. Am J Respir Cell Mol Biol 31: 382-394.

17. Vermeer PD, Harson R, Einwalter LA, Moninger T, Zabner J (2003) Interleukin-9 induces goblet cell hyperplasia during repair of human airway epithelia. $\mathrm{Am} \mathrm{J}$ Respir Cell Mol Biol 28: 286-295.

18. Hayashi T, Ishii A, Nakai S, Hasegawa K (2004) Ultrastructure of goblet-cell metaplasia from Clara cell in the allergic asthmatic airway inflammation in a mouse model of asthma in vivo. Virchows Arch 444: 66-73.

19. Brody AR, Hook GE, Cameron GS, Jetten AM, Butterick CJ, et al. (1987) The differentiation capacity of Clara cells isolated from the lungs of rabbits. Lab Invest 57: 219-229.

20. Kim S, Shim JJ, Burgel PR, Ueki IF, Dao-Pick T, et al. (2002) IL-13-induced Clara cell secretory protein expression in airway epithelium: role of EGFR signaling pathway. Am J Physiol Lung Cell Mol Physiol 283: L67-L75.

21. Nadel JA (2001) Role of epidermal growth factor receptor activation in regulating mucin synthesis. Respir Res 2: 85-89.

22. Takeyama K, Dabbagh K, Lee HM, Agustí C, Lausier JA, et al. (1999) Epidermal growth factor system regulates mucin production in airways. Proc Natl Acad Sci U S A 96: 3081-3086.

23. Tyner JW, Kim EY, Ide K, Pelletier MR, Roswit WT, et al. (2006) Blocking airway mucous cell metaplasia by inhibiting EGFR antiapoptosis and IL-13 transdifferentiation signals. J Clin Invest 116: 309-321.

24. Amishima M, Munakata M, Nasuhara Y, Sato A, Takahashi T, et al. (1998) Expression of epidermal growth factor and epidermal growth factor recepto immunoreactivity in the asthmatic human airway. Am J Respir Crit Care Med 157: 1907-1912

25. Takeyama K, Fahy JV, Nadel JA (2001) Relationship of epidermal growth factor receptors to goblet cell production in human bronchi. Am J Respir Crit Care Med 163: 511-516.

26. Hackel PO, Zwick E, Prenzel N, Ullrich A (1999) Epidermal growth factor receptors: critical mediators of multiple receptor pathways. Curr Opin Cell Biol 11: $184-189$

27. Laoukili J, Perret E, Willems T, Minty A, Parthoens E, et al. (2001) IL-13 alters mucociliary differentiation and ciliary beating of human respiratory epithelia cells. J Clin Invest 108: 1817-1824.

28. Kuperman DA, Huang X, Nguyenvu L, Hölscher C, Brombacher F, et al. (2005) IL-4 receptor signaling in Clara cells is required for allergen-induced mucus production. J Immunol 175: 3746-3752.

29. Atherton HC, Jones G, Danahay H (2003) IL-13-induced changes in the goblet cell density of human bronchial epithelial cell cultures: MAP kinase and phosphatidylinositol 3-kinase regulation. Am J Physiol Lung Cell Mol Physiol 285: L730-739.

30. Danahay H, Atherton H, Jones G, Bridges RJ, Poll CT (2002) Interleukin-13 induces a hypersecretory ion transport phenotype in human bronchial epithelial cells. Am J Physiol Lung Cell Mol Physiol 282: L226-L236.

31. Hoshino M, Morita S, Iwashita H, Sagiya Y, Nagi T, et al. (2002) Increased expression of the human $\mathrm{Ca} 2+$-activated $\mathrm{Cl}$ - channel 1 (CaCC1) gene in the asthmatic airway. Am J Respir Crit Care Med 165: 1132-1136.
32. Singh G, Katyal SL (1997) Clara cells and Clara cell 10 kD protein (CC10). Am J Respir Cell Mol Biol 17: 141-143.

33. Curran DR, Cohn L (2010) Advances in mucous cell metaplasia: a plug for mucus as a therapeutic focus in chronic airway disease. Am J Respir Cell Mol Biol 42: 268-275.

34. Toda M, Tulic MK, Levitt RC, Hamid Q (2002) A calcium-activated chloride channel (HCLCA1) is strongly related to IL-9 expression and mucus production in bronchial epithelium of patients with asthma. J Allergy Clin Immunol 109: 246-250.

35. Kouznetsova I, Chwieralski CE, Bälder R, Hinz M, Braun A, et al. (2007) Induced trefoil factor family 1 expression by trans-differentiating Clara cells in a murine asthma model. Am J Respir Cell Mol Biol 36: 286-295.

36. Young HW, Williams OW, Chandra D, Bellinghausen LK, Pérez G, et al. (2007) Central role of Muc5ac expression in mucous metaplasia and its regulation by conserved 5' elements. Am J Respir Cell Mol Biol 37: 273-290.

37. Wan H, Kaestner KH, Ang SL, Ikegami M, Finkelman FD, et al. (2004) Foxa2 regulates alveolarization and goblet cell hyperplasia. Development 131: 953964.

38. Homer RJ, Zhu Z, Cohn L, Lee CG, White WI, et al. (2006) Differential expression of chitinases identify subsets of murine airway epithelial cells in allergic inflammation. Am J Physiol Lung Cell Mol Physiol 291: L502-511.

39. DeFelice M, Silberschmidt D, DiLauro R, Xu Y, Wert SE, et al. (2003) TTF1 phosphorylation is required for peripheral lung morphogenesis, perinatal survival, and tissue-specific gene expression. J Biol Chem 278: 35574-35583.

40. Park KS, Korfhagen TR, Bruno MD, Kitzmiller JA, Wan H, et al. (2007) SPDEF regulates goblet cell hyperplasia in the airway epithelium. J Clin Invest 117 978-988.

41. Chen G, Korfhagen TR, Xu Y, Kitzmiller J, Wert SE, et al. (2009) SPDEF is required for mouse pulmonary goblet cell differentiation and regulates a network of genes associated with mucus production. J Clin Invest 119: 2914-2924.

42. Evans MJ, Cabral-Anderson LJ, Freeman G (1978) Role of the Clara cell in renewal of the bronchiolar epithelium. Lab Invest 38: 648-653.

43. Holtzman MJ, Battaile JT, Patel AC (2006) Immunogenetic programs for vira induction of mucous cell metaplasia. Am J Respir Cell Mol Biol 35: 29-39.

44. Pawlowski K, Lepisto M, Meinander N, Sivars U, Varga M, et al. (2006) Nove conserved hydrolase domain in the CLCA family of alleged calcium-activated chloride channels. Proteins 63: 424-439.

45. Izuhara K, Ohta S, Shiraishi H, Suzuki S, Taniguchi K, et al. (2009) The mechanism of mucus production in bronchial asthma. Curr Med Chem 16 : 2867-2875.

46. Hoffmann W (2007) TFF (trefoil factor family) peptides and their potential roles for differentiation processes during airway remodeling. Curr Med Chem 14: 2716-2719.

47. LeSimple P, van Seuningen I, Buisine MP, Copin MC, Hinz M, et al. (2007) Trefoil factor family 3 peptide promotes human airway epithelial ciliated cell differentiation. Am J Respir Cell Mol Biol 36: 296-303.

48. Xiang YY, Wang S, Liu M, Hirota JA, Li J, et al. (2007) A GABAergic system in airway epithelium is essential for mucus overproduction in asthma. Nat Med 13: $862-867$.

49. Cohn L, Elias JA, Chupp GL (2004) Asthma: mechanisms of disease persistence and progression. Annu Rev Immunol 22: 789-815.

50. Lee JJ, McGarry MP, Farmer SC, Denzler KL, Larson KA, et al. (1997) Interleukin-5 expression in the lung epithelium of transgenic mice leads to pulmonary changes pathognomonic of asthma. J Exp Med 185: 2143-2156.

51. Cohn L, Homer RJ, MacLeod H, Mohrs M, Brombacher F, et al. (1999) Th2 induced airway mucus production is dependent on IL-4Ralpha, but not on eosinophils. J Immunol 162: 6178-6183.

52. Wills-Karp M, Luyimbazi J, Xu X, Schofield B, Neben TY, et al. (1998) Interleukin-13: central mediator of allergic asthma. Science 282: 2258-2261.

53. Temann UA, Laouar Y, Eynon EE, Homer R, Flavell RA (2007) IL9 leads to airway inflammation by inducing IL13 expression in airway epithelial cells. Int Immunol 19: 1-10. 
Citation: Hayashi T (2012) Molecular Mechanisms of Metaplasia, Differentiation and Hyperplasia of Goblet Cellin Allergic Asthma. J Aller Ther 3:121. doi:10.4172/2155-6121.1000121

54. Fujisawa T, Ide K, Holtzman MJ, Suda T, Suzuki K, et al. (2008) Involvement of the p38 MAPK pathway in IL-13-induced mucous cell metaplasia in mouse tracheal epithelial cells. Respirology 13: 191-202.

55. Heller NM, Matsukura S, Georas SN, Boothby MR, Rothman PB, et al. (2004) Interferon-gamma inhibits STAT6 signal transduction and gene expression in human airway epithelial cells. Am J Respir Cell Mol Biol 31: 573-582.

56. Dickensheets HL, Venkataraman C, Schindler U, Donnelly RP (1999) Interferons inhibit activation of STAT6 by interleukin 4 in human monocytes by inducing SOCS-1 gene expression. Proc Natl Acad Sci U S A 96: 10800-10805.

57. Shi ZO, Fischer MJ, De Sanctis GT, Schuyler MR, Tesfaigzi Y (2002) IFNgamma, but not Fas, mediates reduction of allergen-induced mucous cell metaplasia by inducing apoptosis. J Immunol 168: 4764-4771

58. Stout BA, Melendez K, Seagrave J, Holtzman MJ, Wilson B, et al. (2007) STAT1 activation causes translocation of Bax to the endoplasmic reticulum during the resolution of airway mucous cell hyperplasia by IFN-gamma. J Immunol 178 : 8107-8116.

59. Sehra S, Yao W, Nguyen ET, Ahyi AN, Tuana FM, et al. (2011) Periostin regulates goblet cell metaplasia in a model of allergic airway inflammation. J Immunol 186: 4959-4966.

60. Mabalirajan U, Dinda AK, Kumar S, Roshan R, Gupta P, et al. (2008) Mitochondrial structural changes and dysfunction are associated with experimental allergic asthma. J Immunol 181: 3540-3548.

61. Wen FQ, Kohyama T, Liu X, Zhu YK, Wang H, et al. (2002) Interleukin-4 and interleukin-13-enhanced transforming growth factor-beta2 production in cultured human bronchial epithelial cells is attenuated by interferon-gamma. Am J Respir Cell Mol Biol 26: 484-490.

62. Reader JR, Tepper JS, Schelegle ES, Aldrich MC, Putney LF, et al. (2003) Pathogenesis of mucous cell metaplasia in a murine asthma model. Am J Pathol 162: 2069-2078.

63. Perl AK, Wert SE, Loudy DE, Shan Z, Blair PA, et al. (2005) Conditional recombination reveals distinct subsets of epithelial cells in trachea, bronchi, and alveoli. Am J Respir Cell Mol Biol 33: 455-462.

64. Semenza GL (2001) Hypoxia-inducible factor 1: control of oxygen homeostasis in health and disease. Pediatr Res 49: 614-617.

65. Kim SR, Lee KS, Park HS, Park SJ, Min KH, et al. (2010) HIF-1a inhibition ameliorates an allergic airway disease via VEGF suppression in bronchial epithelium. Eur J Immunol 40: 2858-2869.

66. Ogawa T, Tsubakihara M, Ichikawa M, Kanisawa M (1993) An autoradiographic study of the renewal of mouse bronchiolar epithelium following bromobenzene exposure. Toxicol Pathol 21: 547-553.

67. Otto WR (2002) Lung epithelial stem cells. J Pathol 197: 527-535

68. Reynolds SD, Giangreco A, Power JH, Stripp BR (2000) Neuroepithelial bodies of pulmonary airways serve as a reservoir of progenitor cells capable of epithelial regeneration. Am J Pathol 156: 269-278.

69. Lumsden AB, McLean A, Lamb D (1984) Goblet and Clara cells of human distal airways: evidence for smoking induced changes in their numbers. Thorax 39 : 844-849.

70. Kondo M, Tamaoki J, Takeyama K, Nakata J, Nagai A (2002) Interleukin-13 induces goblet cell differentiation in primary cell culture from Guinea pig tracheal epithelium. Am J Respir Cell Mol Biol 27: 536-541.

71. Araya J, Cambier S, Markovics JA, Wolters P, Jablons D, et al. (2007) Squamous metaplasia amplifies pathologic epithelial-mesenchymal interactions in COPD patients. J Clin Invest 117: 3551-3562.

72. Rawlins EL, Okubo T, Xue Y, Brass DM, Auten RL, et al. (2009) The role of Scgb1a1+ Clara cells in the long-term maintenance and repair of lung airway, but not alveolar, epithelium. Cell Stem Cell 4: 525-534.

73. Guseh JS, Bores SA, Stanger BZ, Zhou Q, Anderson WJ, et al. (2009) Notch signaling promotes airway mucous metaplasia and inhibits alveolar development. Development 136: 1751-1759.

74. Hong KU, Reynolds SD, Watkins S, Fuchs E, Stripp BR (2004) Basal cells are a multipotent progenitor capable of renewing the bronchial epithelium. Am J Pathol 164: 577-588.
75. Hong KU, Reynolds SD, Watkins S, Fuchs E, Stripp BR (2004) In vivo differentiation potential of tracheal basal cells: evidence for multipotent and unipotent subpopulations. Am J Physiol Lung Cell Mol Physiol 286: L643-L649.

76. Nakajima M, Kawanami O, Jin E, Ghazizadeh M, Honda M, et al. (1998) Immunohistochemical and ultrastructural studies of basal cells, Clara cells and bronchiolar cuboidal cells in normal human airways. Pathol Int 48: 944-953.

77. Liu YJ (2001) Dendritic cell subsets and lineages, and their functions in innate and adaptive immunity. Cell 106: 259-262.

78. Liebow AA (1965) patterns of origin and distribution of the major bronchia arteries in man. Am J Anat 117: 19-32.

79. Mitzner W, Lee W, Georgakopoulos D, Wagner E (2000) Angiogenesis in the mouse lung. Am J Pathol 157: 93-101.

80. Randell SH (2006) Airway epithelial stem cells and the pathophysiology of chronic obstructive pulmonary disease. Proc Am Thorac Soc 3: 718-725.

81. Evans MJ, Shami SG, Cabral-Anderson LJ, Dekker NP (1986) Role of nonciliated cells in renewal of the bronchial epithelium of rats exposed to NO2. Am J Pathol 123: 126-133.

82. Breuer R, Zajicek G, Christensen TG, Lucey EC, Snider GL (1990) Cell kinetics of normal adult hamster bronchial epithelium in the steady state. Am J Respir Cell Mol Biol 2: 51-58.

83. Randell SH, Comment CE, Ramaekers FC, Nettesheim P (1991) Propertie of rat tracheal epithelial cells separated based on expression of cell surface alpha-galactosyl end groups. Am J Respir Cell Mol Biol 4: 544-554.

84. Liu JY, Nettesheim P, Randell SH (1994) Growth and differentiation of tracheal epithelial progenitor cells. Am J Physiol 266: L296-L307.

85. Hackett TL, Shaheen F, Johnson A, Wadsworth S, Pechkovsky DV, et al. (2008) Characterization of side population cells from human airway epithelium. Stem Cells 26: 2576-2585

86. Tompkins DH, Besnard V, Lange AW, Wert SE, Keiser AR, et al. (2009) Sox2 is required for maintenance and differentiation of bronchiolar Clara, ciliated, and goblet cells. PLoS One 4: e8248.

87. Mercer RR, Russell ML, Roggli VL, Crapo JD (1994) Cell number and distribution in human and rat airways. Am J Respir Cell Mol Biol 10: 613-624.

88. Hayashi T (2012) Molecular mechanisms in allergic rhinitis: modulation by microbes. Chapter II. Advances in Medicine and Biology 40: 59-90.

89. Kleinjan A, Lambrecht BN (2009) Dendritic cells in rhinitis. Handb Exp Pharmacol: 115-136.

90. Svensson H, Johannisson A, Nikkilä T, Alm GV, Cederblad B (1996) The cell surface phenotype of human natural interferon-alpha producing cells as determined by flow cytometry. Scand J Immunol 44: 164-172.

91. Banchereau J, Briere F, Caux C, Davoust J, Lebecque S, et al. (2000) Immunobiology of dendritic cells. Annu Rev Immunol 18: 767-811.

92. Ekman AK, Erjefält JS, Jansson L, Cardell LO (2011) Allergen-induced accumulation of CD68-,CD123+ dendritic cells in the nasal mucosa. Int Arch Allergy Immunol 155: 234-242.

93. Ito T, Inaba M, Inaba K, Toki J, Sogo S, et al. (1999) A CD1a+/CD11c+ subse of human blood dendritic cells is a direct precursor of Langerhans cells. $J$ Immunol 163: 1409-1419.

94. Tuma E, Rothenfusser S, Hartmann G, Wollenberg B (2002) Identification of $\mathrm{CD} 11 \mathrm{c}+$ myeloid dentritic cells in adenoids and in nasal mucosa of patients with and without allergies. Laryngorhinootologie 81: 580-585.

95. Jahnsen FL, Lund-Johansen F, Dunne JF, Farkas L, Haye R, et al. (2000) Experimentally induced recruitment of plasmacytoid (CD123high) dendritic cells in human nasal allergy. J Immunol 165: 4062-4068.

96. Liu YJ (2007) Thymic stromal lymphopoietin and OX40 ligand pathway in the initiation of dendritic cell-mediated allergic inflammation. J Allergy Clin Immuno 120: $238-244$

97. Kalinski P, Hilkens CM, Wierenga EA, Kapsenberg ML (1999) T-cell priming by type- 1 and type- 2 polarized dendritic cells: the concept of a third signal. Immunol Today 20: 561-567.

98. Pulendran B, Palucka K, Banchereau J (2001) Sensing pathogens and tuning immune responses. Science 293: 253-256. 
Citation: Hayashi T (2012) Molecular Mechanisms of Metaplasia, Differentiation and Hyperplasia of Goblet Cellin Allergic Asthma. J Aller Ther 3:121. doi:10.4172/2155-6121.1000121

Page 10 of 10

99. Soumelis V, Reche PA, Kanzler H, Yuan W, Edward G, et al. (2002) Human epithelial cells trigger dendritic cell mediated allergic inflammation by producing TSLP. Nat Immunol 3: 673-680.

100. Wang Y, Bai C, Li K, Adler KB, Wang X (2008) Role of airway epithelial cells in development of asthma and allergic rhinitis. Respir Med 102: 949-955.

101. Ito T, Wang YH, Duramad O, Hori T, Delespesse GJ, et al. (2005) TSLPactivated dendritic cells induce an inflammatory $T$ helper type 2 cell response through OX40 ligand. J Exp Med 202: 1213-1223.

102. Isaksen DE, Baumann H, Zhou B, Nivollet S, Farr AG, et al. (2002) Uncoupling of proliferation and Stat5 activation in thymic stromal lymphopoietin-mediated signal transduction. J Immunol 168: 3288-3294.

103.Zemke AC, Snyder JC, Brockway BL, Drake JA, Reynolds SD, et al. (2009) Molecular staging of epithelial maturation using secretory cell-specific genes as markers. Am J Respir Cell Mol Biol 40: 340-348.

104. Moghal N, Neel BG (1998) Integration of growth factor, extracellular matrix, and retinoid signals during bronchial epithelial cell differentiation. Mol Cell Biol 18: 6666-6678.

105.Dvorak A, Tilley AE, Shaykhiev R, Wang R, Crystal RG (2011) Do airway epithelium air-liquid cultures represent the in vivo airway epithelium transcriptome? Am J Respir Cell Mol Biol 44: 465-473.

106. Tang ML, Wilson JW, Stewart AG, Royce SG (2006) Airway remodelling in asthma: current understanding and implications for future therapies. Pharmacol Ther 112: 474-488.
107. Holgate ST (2007) The epithelium takes centre stage in asthma and atopic dermatitis. Trends Immunol 28: 248-251.

108. Lei L, Zhang Y, Yao W, Kaplan MH, Zhou B (2011) Thymic stromal lymphopoietin interferes with airway tolerance by suppressing the generation of antigen-specific regulatory T cells. J Immunol 186: 2254-2261.

109. Servais S, Boussouar A, Molnar A, Douki T, Pequignot JM, et al. (2005) Agerelated sensitivity to lung oxidative stress during ozone exposure. Free Radic Res 39: 305-316.

110. Heinzmann A, Deichmann KA (2001) Genes for atopy and asthma. Curr Opin Allergy Clin Immunol 1: 387-392

111. Heinzmann A, Thoma C, Dietrich H, Deichmann KA (2003) Identification of common polymorphisms in the mitochondrial genome. Allergy 58: 830-831.

112. Raby BA, Klanderman B, Murphy A, Mazza S, Camargo CA Jr, et al. (2007) A common mitochondrial haplogroup is associated with elevated total serum IgE levels. J Allergy Clin Immunol 120: 351-358.

113. Aguilera-Aguirre L, Bacsi A, Saavedra-Molina A, Kurosky A, Sur S, et al (2009) Mitochondrial dysfunction increases allergic airway inflammation. J Immunol 183: 5379-5387.

114. Mabalirajan U, Dinda AK, Kumar S, Roshan R, Gupta P, et al. (2009) Mitochondrial dysfunction increases allergic airway inflammation. J Immunol 183: $5379-5387$.

115. Comhair SA, Bhathena PR, Dweik RA, Kavuru M, Erzurum SC (2000) Rapid loss of superoxide dismutase activity during antigen-induced asthmatic response. Lancet 355: 624. 